\title{
Familial intergenerational and maternal aggregation patterns in nutrient intakes in the Lifeways Cross-Generation Cohort Study
}

\author{
Aakash Shrivastava ${ }^{1}$, Celine Murrin ${ }^{1}$, Mary Rose Sweeney ${ }^{2}$, Patricia Heavey ${ }^{1}$ and \\ Cecily C Kelleher ${ }^{1, *}$ for the Lifeways Cohort Study Steering Group \\ ${ }^{1}$ National Nutrition Surveillance Centre and Health Research Board Centre for Diet and Health Research, UCD \\ School of Public Health, Physiotherapy and Population Science, Woodview House, University College Dublin, \\ Belfield, Dublin 4, Ireland: ${ }^{2}$ School of Nursing, Dublin City University, Dublin, Ireland
}

Submitted 12 September 2011: Final revision received 5 May 2012: Accepted 17 June 2012: First published online 13 August 2012

\begin{abstract}
Objective: The current study prospectively examines the intra-uterine hypothesis by comparing maternal, paternal and grandparental lineage influences on children's diet and also maternal-child aggregation patterns during pregnancy and early childhood. Design: Prenatal dietary information was available for expectant mothers, fathers and up to four grandparents through a detailed validated semi-quantitative FFQ. At 6-year follow-up, when children averaged 5 years of age, dietary information was re-collected for mothers and a subset of maternal grandmothers using the same FFQ. Child's FFQ version was used for children. Anthropometric and sociodemographic variables were also collected.

Settings: Three-generation familial cohort representative of the contemporary Irish national population.

Subjects: Children aged 5 years $(n 567)$ and their parents and grandparents.

Results: Associations for energy, macronutrient and fibre intakes were compared using Pearson's correlations, intra-class correlations (ICC) and linear regression models, adjusted for energy and potential confounders. Significant, moderatestrength positive correlations were observed for nutrient intakes in children's nuclear families (ICC (range) $=0 \cdot 22-0 \cdot 28)$. The father-child associations $(r$ (range) $=$ $0 \cdot 13-0 \cdot 20)$ were weaker than the mother-child associations $(r$ (range $)=0 \cdot 14-0 \cdot 33$ ) In general, associations were stronger for maternal postnatal intake-child intake than for maternal prenatal intake-child intake, except for percentage of energy from fat (adjusted $\beta=0 \cdot 16,95 \%$ CI $0 \cdot 05,0 \cdot 26 ; P=0 \cdot 004$ ), which was stronger for maternal prenatal intake, specifically in non-breast-fed children (adjusted $\beta=0 \cdot 28,95 \% \mathrm{CI}$ $0 \cdot 12,0 \cdot 44 ; P=0 \cdot 001)$. Among all grandparents, correlations were significant only for maternal grandmother-mother pairs $(r$ (range $)=0 \cdot 10-0 \cdot 36)$. Significant positive ICC were observed for nutrient intakes of maternal grandmother-mother-child triads $($ ICC $($ range $)=0 \cdot 12-0 \cdot 27)$, not found in paternal lines.

Conclusions: These findings suggest that maternal-environment programming influences dietary intake.
\end{abstract}

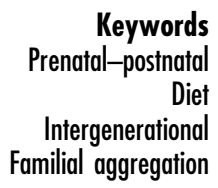

The extent to which food and nutrient patterns cluster or aggregate within families has considerable public health importance. This is particularly relevant given the rising trends in early childhood obesity and subsequent related chronic disease patterns, now seen in most countries worldwide. Yet there is a relative paucity of research on familial aggregation of dietary intake. Wang et $a l^{(1)}$ recently performed a systematic review on parent-child resemblances for food and nutrient intakes. Their search resulted in only twenty-four studies of satisfactory methodological quality suitable for review. Of these, very few were from large national samples and most were from the American continent.
Nuclear families may share common genes and home environment. Twin studies on dietary preferences and intake have shown that genetic predisposition partially explains this familial resemblance ${ }^{(2-5)}$. Parents may also influence children's food preferences and behaviour through food provision, role modelling and parenting patterns ${ }^{(6,7)}$. In their review, Wang et al. ${ }^{(1)}$ concluded that there was a definite parent-child intake resemblance, although it was weak to moderate in strength. The same was true for studies on pre-school children ${ }^{(8-10)}$.

Not many studies have paternal dietary information and only a few with such data have analysed paternalchild intakes separately from maternal-child intakes, to 
allow parent-of-origin comparisons. Also, to our knowledge there is only one three-generation study on familial intake which again was limited to examining the female line (maternal grandmothers, mothers and daughters) as adults ${ }^{(11)}$. Although these studies discussed the possibility of the genetic and home-environmental influence as explanations for their observed familial dietary aggregation patterns, they did not sufficiently explain why the maternal-line associations in their findings were stronger.

Studies comparing the influence of prenatal and postnatal maternal dietary intake on offspring's diet are also rare. Brion et al. ${ }^{(12)}$, the first to publish such a comparison, showed that maternal macronutrient intake at 32 weeks of pregnancy and 47 months postnatally were each positively associated with their children's intake, and further, that these maternal associations were stronger than those for paternal intake. They also demonstrated that associations of maternal prenatal-child intake patterns were greater than maternal postnatal-child intake, specifically for protein and fat. This Avon Longitudinal Study of Parents and Children (ALSPAC) concluded that these findings demonstrated evidence of in utero programming of children's dietary behaviours.

The aim of the present analysis was to examine patterns of familial aggregation of dietary intake in the Lifeways Cross-Generation Cohort Study. We sought to examine the existence, direction and magnitude of parental associations for children's dietary intake when they averaged 5 years of age. To assess intra-uterine influences on offspring's diet, we first contrasted the parent-of-origin associations, the maternal-child associations with paternal-child associations for dietary intake. These comparisons were made for maternal and paternal intake measured during pregnancy and additionally for maternal intake 5 years postnatally. Second, we compared the associations of child's dietary intake with maternal intake during pregnancy and maternal intake 5 years postnatally. Finally we tested our hypothesis on intra-uterine influences by comparing aggregation in maternal and paternal lines of three generations.

\section{Methods}

Lifeways is a three-generation Irish familial cohort that was established in 2001-2003; the recruitment procedure has been described previously ${ }^{(13)}$. The a priori purpose of establishing the cohort was to examine familial and cross-generation influences on early childhood development over the first 5 years of children's lives, studying development and health in a life course perspective.

In brief, mothers were recruited at first booking visit during pregnancy in two regional maternity hospitals in Galway (west) and Dublin (east) at which point (time 1, T1) they completed a health status questionnaire, including a semi-quantitative food frequency (SQFFQ) instrument containing 149 food and drink items developed for surveillance purposes in the Republic of Ireland from the European Prospective Investigation into Cancer and Nutrition (EPIC) ${ }^{(14)}$. This instrument was validated for an Irish adult population using food diary and protein biomarker studies ${ }^{(15)}$. Each expectant mother provided information on her habitual diet since conception. In the health status questionnaire each mother also provided information on her pre-pregnancy anthropometric measures, including height and weight, and other sociodemographic variables. It was aimed, if possible, to include the mother's male partner and at least one grandparent. These adults also completed the same questionnaire as the mothers at baseline and, along with anthropometric measures and other sociodemographic variables, provided information on their habitual diet for the last year. Live infants were subsequently added to the cohort with hospital maternity linkage information.

In 2007-2008, when these children averaged 5 years of age (time 2, T2), mothers were asked to repeat the health assessment questionnaire, including reported dietary intake, and to provide information also on their child's health status, including dietary intake. Mothers responded for themselves on the same SQFFQ as earlier and again reported habitual diet for the previous year. The SQFFQ containing fifty-two food and drink items used for assessment of children's diet was comparatively different and adapted from the UK National Diet and Nutrition Survey of $4 \cdot 5$-year-old children ${ }^{(16)}$. The mothers' and children's SQFFQ were also validated in the Lifeways study using a $7 \mathrm{~d}$ weighed food diary in a sub-sample prior to follow-up stage of the study ${ }^{(17)}$. Mothers also provided information on children's breast-feeding and child-care attendance (both institutional and noninstitutional). Mothers and children were offered an examination for height, weight and waist circumference as well, to a standardised protocol ${ }^{(17)}$. At the same time in 2007-2008, a repeat dietary assessment with the same adult SQFFQ instrument was undertaken for a sub-set of these grandparents residing in the greater Dublin area only. Figure 1 provides a schematic representation of data collection relevant to this analysis.

Nutrient conversion was undertaken using McCance and Widdowson's food composition tables ${ }^{(18)}$ with the program FFQ_Software $\left.{ }^{(}\right)$version $1 \cdot 0$ developed specially by the National Nutrition Surveillance Centre, School of Public Health and Population Science, University College Dublin. Dietary data were logarithm-transformed to improve normality. Pearson's correlations were undertaken for energy, macronutrient and fibre intakes in cohort member pairs (dyads), in unadjusted, adjusted for energy and fully adjusted models. Family correlation is a well-accepted behavioural genetic strategy design to analyse if behavioural traits run in families ${ }^{(19)}$. Energy adjustments were made by the multivariate nutrient density model method ${ }^{(20,21)}$. Nutrients were converted to nutrient densities by computing percentage of energy for 


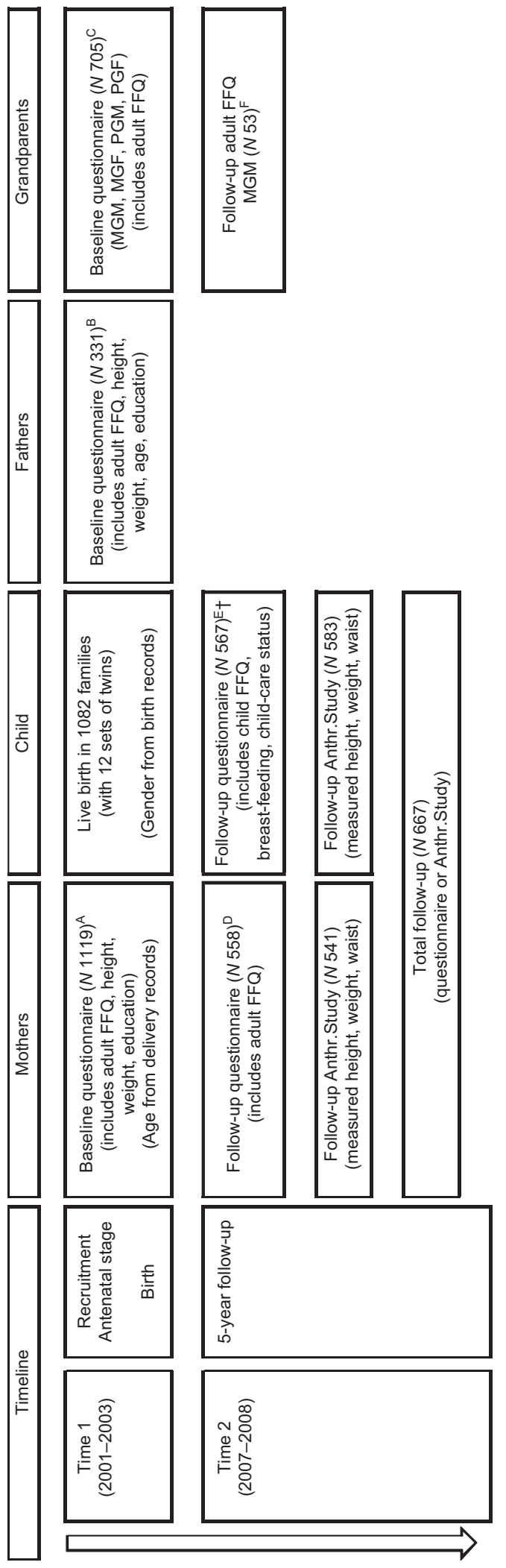

Fig. 1 Schematic representation of time points and data available for analysis ( ${ }^{\mathrm{A}-\mathrm{F}}$ corresponding figures in Table 1; †core analysis group; MGM, maternal grandmothers; MGF, maternal grandfathers; PGM, paternal grandmothers; PGF, paternal grandfathers; Anthr.Study, anthropometric measurement study) protein, fat and carbohydrate and dividing fibre intake by $4184 \mathrm{~kJ}$ ( $1000 \mathrm{kcal})$. Statistical tests were computed on nutrient densities with additional adjustment for energy variables as covariates. The fully adjusted model additionally adjusted for children's gender, height, BMI and for parents' age, height, BMI and education level.

Intra-class correlations (ICC) were also undertaken, first for three nuclear family triads (that of child and parents, mother and her parents and father and his parents) and second for extended families, in maternal and paternal lines (child, parent, grandparents). ICC implied that intake among individuals of the same family (within-family) was more alike than among individuals from different families (between-family) ${ }^{(22,23)}$.

Finally, maternal prenatal-postnatal comparisons were made using independent linear regression models for children's energy intake and each of the nutrients. The regression of children's intake for the nutrient of interest (dependent variable) $v$. mothers' prenatal (T1) and postnatal (T2) intake for the same nutrient (independent variables) was performed. Similar to correlations analyses, linear regressions were computed in unadjusted, energy-adjusted and fully adjusted models. These fully adjusted models additionally adjusted for the use of child-care services and were also stratified for breast-fed and non-breast-fed children. All analyses were made using the SPPS statistical software package version $15 \cdot 0$.

Ethical approval for the Lifeways study was obtained from ethical committees of Coombe University Hospital, Dublin, University College Dublin, the Irish College of General Practitioners and University College Hospital Galway, Ireland.

\section{Results}

Of 1119 expectant mothers with FFQ data, 1082 gave birth to a live infant; 331 fathers, 283 maternal grandmothers, 163 maternal grandfathers, 163 paternal grandmothers and ninety-six paternal grandfathers also participated in the dietary study at the antenatal stage (T1). In the 2007-2008 follow-up (T2), 558 mothers, 567 children and fifty-three maternal grandmothers provided dietary information. As the participation of grandparents at follow-up (T2) was small, for the purposes of the present analysis only maternal grandmothers were considered. Exact numbers of available FFQ for participating family member pairs (dyads) from singleton baby (non-twin) families are given in Table 1.

Table 2 gives the unadjusted correlations for energy $(\mathrm{kJ})$, protein, fat, carbohydrate and fibre intakes (all in grams) between all family member dyads of this cohort. It shows clear relationships in intakes for the child's nuclear family, i.e. mother-child-father. Only the father's fat intake was not correlated with that of his child. The positive correlations in the child's nuclear family were of 
Table 1 Number of FFQ data $(M)$ and FFQ pairs $(n)$ available at antenatal (T1) and follow-up (T2) stages: Lifeways Cross-Generation Cohort Study, Republic of Ireland

\begin{tabular}{|c|c|c|c|c|c|c|c|c|}
\hline & $\begin{array}{c}\text { Mothers } \\
(\mathrm{T} 1 ; N 1119)^{\mathrm{A}}\end{array}$ & $\begin{array}{c}\text { Mothers } \\
(\mathrm{T} 2 ; N 558)^{\mathrm{D}}\end{array}$ & $\begin{array}{c}\text { Fathers } \\
(\mathrm{T} 1 ; N 331)^{\mathrm{B}}\end{array}$ & $\begin{array}{c}\text { MGM } \\
(\mathrm{T} 1 ; N 283)^{\mathrm{C}}\end{array}$ & $\begin{array}{c}\text { MGM } \\
(\mathrm{T} 2 ; N 53)^{\mathrm{F}}\end{array}$ & $\begin{array}{c}\text { MGF } \\
(\mathrm{T} 1 ; N 163)^{\mathrm{C}}\end{array}$ & $\begin{array}{c}\text { PGM } \\
(\mathrm{T} 1 ; N 163)^{\mathrm{C}}\end{array}$ & $\begin{array}{c}\text { PGF } \\
(\mathrm{T} 1 ; N 96)^{\mathrm{C}}\end{array}$ \\
\hline $\begin{array}{l}\text { Children (T2; } N 567)^{\mathrm{E}} /(N 552 \text { singleton children) }+ \\
\text { Mothers (T1) } \\
\text { Mothers (T2) } \\
\text { Fathers (T1) }\end{array}$ & $n 545$ & $n 551$ & $\begin{array}{l}n 229 \\
n 329 \\
n 234\end{array}$ & $\begin{array}{l}n 282 \\
n 181\end{array}$ & $\begin{array}{l}n 53 \\
n 37\end{array}$ & $n 161$ & $n 86$ & $n 51$ \\
\hline
\end{tabular}

T1, prenatal stage time point; T2, follow-up stage time point (postnatal); MGM, maternal grandmothers; MGF, maternal grandfathers; PGM, paternal grandmothers; PGF, paternal grandfathers; $N$, total FFQ in sample; $n$, $\mathrm{FFQ}$ in pairs (dyads) for singleton baby families.

tCore analysis group.

Table 2 Pearson's correlations for energy, macronutrient and fibre intakes in family member dyads (unadjusted model): Lifeways Cross-Generation Cohort Study, Republic of Ireland

\begin{tabular}{|c|c|c|c|c|c|c|c|c|}
\hline & \multicolumn{2}{|c|}{ Mother (T1)-child (T2) } & \multicolumn{2}{|c|}{ Mother (T2)-child (T2) } & \multicolumn{2}{|c|}{ Father (T1)-child (T2) } & \multirow{2}{*}{$\begin{array}{c}\text { Mother (T1)- } \\
\text { father (T1) }\end{array}$} & \multirow{2}{*}{$\begin{array}{c}\begin{array}{c}\text { Mother (T2) } \\
\text { father (T1) }\end{array} \\
r\end{array}$} \\
\hline & $r$ & $95 \% \mathrm{Cl}$ & $r$ & $95 \% \mathrm{Cl}$ & $r$ & $95 \% \mathrm{Cl}$ & & \\
\hline Energy (kJ) & $0 \cdot 19^{\star \star}$ & $0.11,0.27$ & $0.31^{\star *}$ & $0.24,0.39$ & $0 \cdot 13^{*}$ & $0.00,0.26$ & $0 \cdot 19^{\star \star}$ & $0.24^{\star \star}$ \\
\hline Protein $(\mathrm{g})$ & $0 \cdot 18^{\star *}$ & $0.10,0.26$ & $0 \cdot 27^{* *}$ & $0.19,0.35$ & $0 \cdot 13^{*}$ & $0.00,0.26$ & $0 \cdot 12^{*}$ & $0 \cdot 13^{*}$ \\
\hline Fat $(\mathrm{g})$ & $0 \cdot 15^{\star \star}$ & $0.07,0.23$ & $0 \cdot 25^{\star \star}$ & $0.17,0.33$ & 0.05 & $-0.08,0.18$ & $0 \cdot 17^{\star \star}$ & $0.22^{\star \star}$ \\
\hline Carbohydrate (g) & $0 \cdot 14^{\star *}$ & $0.06,0.23$ & $0 \cdot 27^{\star *}$ & $0.19,0.35$ & $0 \cdot 15^{\star}$ & $0.02,0.27$ & $0 \cdot 19^{\star \star}$ & $0.22^{\star \star}$ \\
\hline \multirow[t]{3}{*}{ Fibre $(\mathrm{g})$} & $0 \cdot 15^{\star *}$ & $0.07,0.23$ & $0.33^{* *}$ & $0 \cdot 25,0.40$ & $0 \cdot 20^{* *}$ & $0.07,0.32$ & $0 \cdot 21^{\star *}$ & $0 \cdot 18^{* *}$ \\
\hline & $\begin{array}{l}\text { MGM (T1)- } \\
\text { mother (T1) }\end{array}$ & $\begin{array}{l}\text { MGM (T1)- } \\
\text { mother (T2) }\end{array}$ & $\begin{array}{l}\text { MGM (T2)- } \\
\text { mother (T1) }\end{array}$ & $\begin{array}{l}\text { MGM (T2)- } \\
\text { mother (T2) }\end{array}$ & $\begin{array}{l}\text { MGF (T1)- } \\
\text { mother (T1) }\end{array}$ & $\begin{array}{l}\text { PGM (T1)- } \\
\text { father (T1) }\end{array}$ & $\begin{array}{l}\text { PGF (T1)- } \\
\text { father (T1) }\end{array}$ & \\
\hline & $r$ & $r$ & $r$ & $r$ & $r$ & $r$ & $r$ & \\
\hline$\overline{\text { Energy (kJ) }}$ & 0.06 & 0.08 & $0 \cdot 25^{(*)}$ & $0 \cdot 29^{(*)}$ & -0.04 & $-0 \cdot 24$ & -0.09 & \\
\hline Protein $(\mathrm{g})$ & $0 \cdot 10^{*}$ & 0.11 & $0 \cdot 30^{*}$ & $0.34^{*}$ & -0.06 & $-0 \cdot 18$ & -0.05 & \\
\hline Fat $(\mathrm{g})$ & 0.07 & 0.06 & $0 \cdot 27^{*}$ & $0 \cdot 36^{*}$ & 0.05 & $-0 \cdot 16$ & $-0 \cdot 18$ & \\
\hline Carbohydrate (g) & 0.06 & 0.08 & $0 \cdot 12$ & $0 \cdot 26$ & -0.08 & -0.25 & 0.08 & \\
\hline Fibre (g) & $0 \cdot 15^{\star}$ & $0 \cdot 12$ & -0.05 & $0 \cdot 18$ & -0.04 & -0.08 & $0 \cdot 17$ & \\
\hline
\end{tabular}

T1, prenatal stage time point; T2, follow-up stage time point (postnatal); MGM, maternal grandmothers; MGF, maternal grandfathers; PGM, paternal grandmothers; PGF, paternal grandfathers.

T*) prenatal stage time point; T2, follow-up stage
$\left({ }^{*}<0 \cdot 1,{ }^{*} P<0 \cdot 05,{ }^{\star \star} P<0 \cdot 01\right.$ (all two-tailed). 
modest strength, but statistically significant, with the mother-child correlations $(r \leq 0.33)$ being stronger than the father-child ones $(r \leq 0 \cdot 20)$. The positive correlations observed for mother-child dietary intake were generally stronger for the maternal postnatal $(\mathrm{T} 2) \operatorname{diet}(r$ (range) $=$ $0 \cdot 25-0.33)$ than for the maternal prenatal (T1) diet $(r$ (range $)=0 \cdot 14-0 \cdot 19)$. There was also a direct pattern of association between the maternal grandmother's dietary intake and that of her daughter at both time points $(r \leq 0 \cdot 36)$. Other than the maternal grandmothers, none of the other grandparents showed any significant dietary associations.

Table 3 shows the correlations for energy-adjusted nutrient intakes. The correlations were largely reduced or weakened in this model. However, the mother-child correlations $(r \leq 0 \cdot 23)$ were still stronger than those for the father $(r \leq 0 \cdot 14)$ and again generally stronger associations were observed with maternal postnatal (T2) intake $(r \leq 0 \cdot 23)$. The exception was fat intake, which appeared to be borderline significant only for the maternal prenatal (T1) intake $(r=0 \cdot 08, P=0 \cdot 08)$. Maternal grandmother's fat $(r=0 \cdot 15)$ and fibre $(r=0 \cdot 25)$ intakes continued to correlate positively and significantly with those of her daughter.

Table 4 shows the correlations in the fully adjusted models for the child's nuclear family. Mother-child positive and statistically significant correlations $(r$ (range) $=$ $0 \cdot 11-0 \cdot 29)$ were still seen at both time points, but the father-child correlations attenuated and were no longer statistically significant. The maternal postnatal intake-child intake positive correlations were again stronger than for maternal prenatal intake-child intake as seen with energy $(r=0 \cdot 29)$, protein $(r=0 \cdot 11)$ and fibre $(r=0 \cdot 21)$. However, the maternal prenatal intake-child intake was now significantly stronger for fat $(r=0 \cdot 17, P=0 \cdot 001)$.

Table 5 shows the ICC results in family triads and extended three-generation family lines. A statistically significant homogeneity was found in energy and nutrient intakes of the child's nuclear family (ICC (range) $=$ $0 \cdot 22-0 \cdot 28$ ) and also in the mother's nuclear family (ICC $($ range $)=0 \cdot 08-0 \cdot 19)$ although they were comparatively weaker in strength. However, there were no significant correlations for the father's family. When comparisons were made in extended family lines involving only parents and grandparents of concerned lineage, the ICC were again significant in the maternal family line (ICC (range)= $0 \cdot 09-0 \cdot 19$ ) and not in the paternal family line (ICC (range) $=-0.04$ to $0 \cdot 09$ ). Finally, removal of the maternal grandfather from the maternal family line further improved the correlation strengths for maternal grandmothermother-child triads, suggesting a stronger homogeneity in their dietary intake (ICC (range) $=0 \cdot 12-0 \cdot 27$ ). These findings confirm familial resemblances in dietary intake patterns for the children's nuclear family and also in the maternal line, but not the paternal line.

Table 6 shows the unadjusted, energy-adjusted and fully adjusted linear regression models. The models show

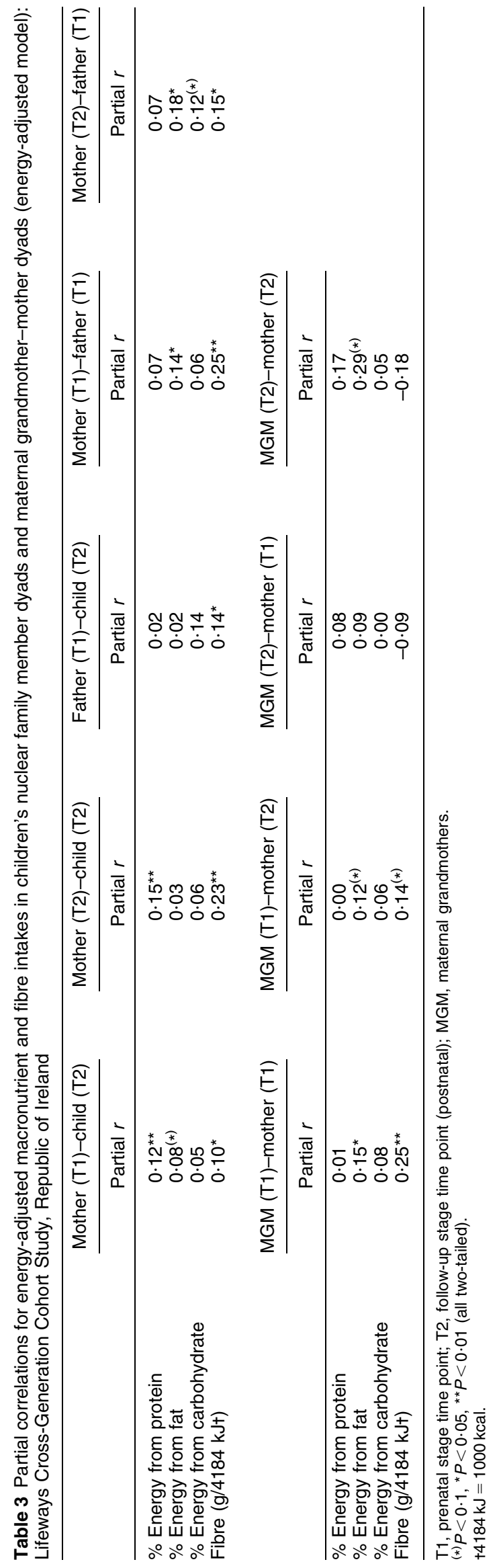


Table 4 Partial correlations for fully adjustedt energy, macronutrient and fibre intakes in children's nuclear family member dyads (full adjusted model): Lifeways Cross-Generation Cohort Study, Republic of Ireland

\begin{tabular}{|c|c|c|c|}
\hline & Mother (T1)-child (T2) & Mother (T2)-child (T2) & Father (T1)-child (T2) \\
\hline & Partial $r$ & Partial $r$ & Partial $r$ \\
\hline Energy (kJ) & $0 \cdot 15^{\star \star}$ & $0 \cdot 29^{\star \star}$ & $0 \cdot 11$ \\
\hline$\%$ Energy from protein & 0.06 & $0 \cdot 11^{*}$ & -0.01 \\
\hline$\%$ Energy from fat & $0 \cdot 17^{\star \star}$ & 0.06 & -0.02 \\
\hline \% Energy from carbohydrate & $0 \cdot 10^{(*)}$ & 0.07 & 0.03 \\
\hline Fibre (g/4184 kJł) & 0.08 & $0 \cdot 21^{\star \star}$ & $0 \cdot 14^{(*)}$ \\
\hline
\end{tabular}

${ }^{(*)} P<0.1,{ }^{*} P<0.05,{ }^{* *} P<0.01$ (all two-tailed).

tAdjusted for children's characteristics: gender, height $(\mathrm{cm}), \mathrm{BMI}\left(\mathrm{kg} / \mathrm{m}^{2}\right)$; parents' characteristics: age (years), height $(\mathrm{cm}), \mathrm{BMI}(\mathrm{kg} /$ $\mathrm{m}^{2}$ ), education status; and additional adjustment of energy $(\mathrm{kJ})$ of children and parents. $\ddagger 4184 \mathrm{~kJ}=1000 \mathrm{kcal}$.

the same pattern as seen in correlation models for the maternal-child dyads. The maternal-child intake associations were generally stronger for maternal postnatal (T2) diet (energy, percentage of energy from protein, energy-adjusted fibre), with exception of the percentage of energy from fat which, although modest in magnitude, was statistically highly significant for maternal prenatal (T1) intake (adjusted $\beta=0 \cdot 16,95 \%$ CI $0 \cdot 05,0 \cdot 26$; $P=0 \cdot 004)$. In the fully adjusted models the child gender variable and the variable on history of child-care use were neither statistically significant nor made appreciable change to observed associations.

The fully adjusted models stratified by history of breastfeeding showed that maternal-child intake associations for percentage of energy from protein were observed only for breast-fed children and the associations for energy and energy-adjusted fibre were also relatively stronger for breast-fed children. These associations were again stronger with maternal postnatal intake. However, the earlier observed association between maternal prenatal-child intake for percentage of energy from fat was seen only in non-breast-fed children (adjusted $\beta=0 \cdot 28,95 \%$ CI $0 \cdot 12,0 \cdot 44 ; P=0 \cdot 001$ ).

\section{Discussion}

We have shown statistically significant patterns of dietary intake associations of moderate strength and positive direction in the children's nuclear family in this contemporary birth cohort study. The findings are consistent with the direction and magnitude of association reported by Wang et al. ${ }^{(1)}$ in their recently published meta-analysis on parent-child resemblance studies for dietary intake, suggesting a coherent familial association, not just by chance. The magnitude of the association is also consistent with a meta-analysis on parent-child resemblance studies for food preferences, instead of intakes ${ }^{(24)}$.

We have also demonstrated that maternal-child dietary resemblances are stronger than paternal-child dietary resemblances at both prenatal and postnatal time points. The fact that the mother provided responses for both herself and her child could be a possible reason for stronger maternal associations. However, a number of methodological steps, as detailed in the 'Methods' section, were taken to minimise the possibility of such a bias. First, the study employed FFQ of different design for mothers and children, so a mother could not easily replicate in one section what was recorded in another; the adult and child FFQ versions were adopted from different international studies. Second, at the follow-up stage, a subset of mothers' and children's FFQ was validated using a $7 \mathrm{~d}$ weighed food diary under the supervision of researchers making home visits. The maternal-paternal differences were also observed at the prenatal time point, recorded by both parents 6 years before the mothers recorded the child's intake; thus it is unlikely that the stronger maternal-child associations are solely due to bias.

The finding of stronger maternal-child dietary resemblances is again consistent with that of previous comparable studies ${ }^{(8,23,25,26)}$. Demonstrating a stronger maternal association compared with paternal association in itself suggests a unique relationship between mother and child, potentially an intra-uterine mechanism of influence on offspring's outcome.

It might be argued that mothers' influence on children in their shared home environment would be stronger than that of fathers. However, we were able to further validate our finding by contrasting associations for parental exposure at the time of pregnancy itself. DaveySmith et al. contend that demonstrating that maternal exposure during pregnancy has a stronger influence than paternal exposure is a robust method of showing that child outcome is due to intra-uterine exposure ${ }^{(27,28)}$. For the first time, we have shown this effect using maternal and paternal dietary intake both measured at 14-20 weeks of pregnancy and the resulting parent-child intake association patterns were consistent with those that Brion et $a l^{(12)}$ demonstrated with ALSPAC cohort data, contrasting maternal intake at 32 weeks' gestation with paternal intake 47 months postnatally.

We also found that maternal prenatal-offspring fat intake associations were stronger than maternal postnataloffspring fat intake associations, a finding in respect to fat 
Table 5 Intra-class correlations (ICC) between nuclear family triads and extended maternal v. paternal family lines: Lifeways Cross-Generation Cohort Study, Republic of Ireland

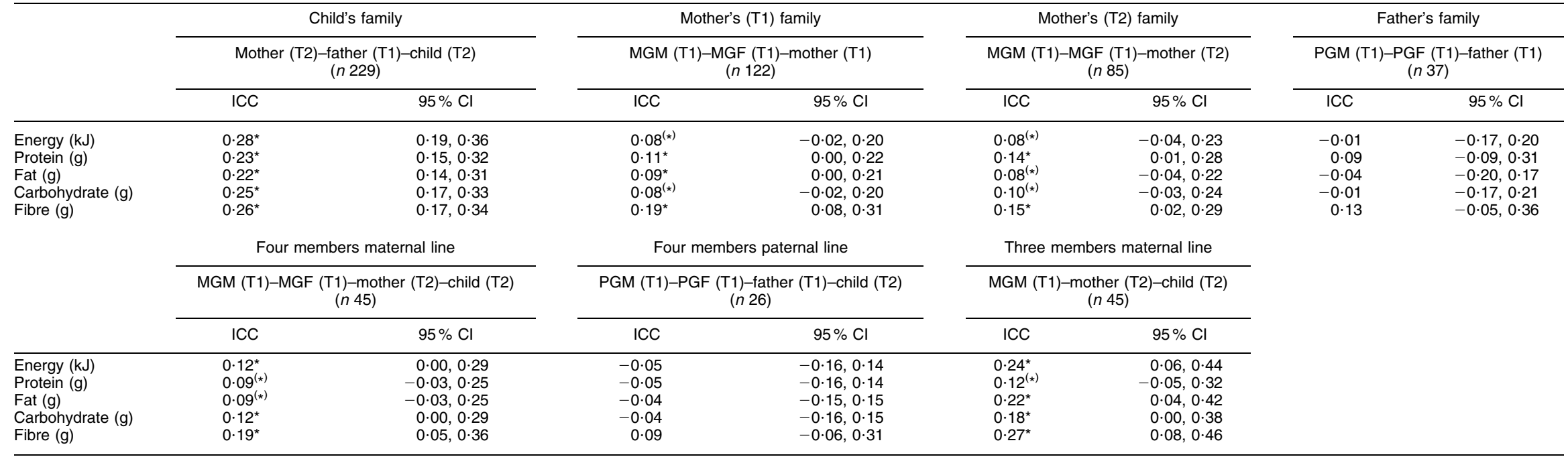

T1, prenatal; T2, postnatal; MGM, maternal grandmothers; MGF, maternal grandfathers; PGM, paternal grandmothers; PGF, paternal grandfathers.

$\left.{ }^{*}\right) P<0 \cdot 1,{ }^{\star} P<0.05$ (all two-tailed).

Table 6 Results from regression of children's energy, macronutrient and fibre intakes $v$. mothers' prenatal and mothers' postnatal energy, macronutrient and fibre intakes ( $n$ 544): Lifeways Cross-Generation Cohort Study, Republic of Ireland

\begin{tabular}{|c|c|c|c|c|c|c|c|c|c|c|c|c|c|c|}
\hline \multicolumn{3}{|c|}{$\begin{array}{l}\text { Unadjusted model } \\
\qquad(n 544)\end{array}$} & \multicolumn{3}{|l|}{$\begin{array}{l}\text { Energy-adjusted model } \\
\qquad(n 544)\end{array}$} & \multicolumn{3}{|c|}{$\begin{array}{l}\text { Fully adjusted model } \\
\qquad(n 419)+\end{array}$} & \multicolumn{3}{|c|}{$\begin{array}{l}\text { Breast-fed fully adjusted } \\
\qquad(n \text { 217)+, } \neq\end{array}$} & \multicolumn{3}{|c|}{$\begin{array}{l}\text { Not breast-fed fully adjusted } \\
\qquad(n \text { 190)+, }\end{array}$} \\
\hline & $\operatorname{Std} \beta$ & $P$ & & $\operatorname{Std} \beta$ & $P$ & $\operatorname{Std} \beta$ & $95 \% \mathrm{Cl}$ & $P$ & $\operatorname{Std} \beta$ & $95 \% \mathrm{Cl}$ & $P$ & $\operatorname{Std} \beta$ & $95 \% \mathrm{Cl}$ & $P$ \\
\hline \multicolumn{15}{|l|}{ Child's energy (kJ) } \\
\hline Mother's T1 energy (kJ) & 0.115 & 0.007 & & & & 0.096 & $-0 \cdot 00,0 \cdot 19$ & 0.055 & 0.078 & $-0.06,0.22$ & $0 \cdot 27$ & $0 \cdot 131$ & $-0.01,0.28$ & 0.07 \\
\hline $\begin{array}{l}\text { Mother's T2 energy (kJ) } \\
\text { Child's protein (a) }\end{array}$ & $0 \cdot 282$ & 0.000 & Child's \% eneray from protein & & & 0.259 & $0.16,0.35$ & 0.000 & 0.275 & $0.14,0.42$ & 0.000 & 0.221 & $0.08,0.36$ & 0.003 \\
\hline Mother's T1 protein (g) & 0.116 & 0.007 & Mother's T1 \% energy from protein & 0.087 & 0.05 & 0.063 & $-0.04,0 \cdot 16$ & 0.21 & 0.017 & $-0 \cdot 12,0 \cdot 15$ & 0.81 & 0.076 & $-0.08,0.23$ & 0.34 \\
\hline $\begin{array}{l}\text { Mother's T2 protein (g) } \\
\text { Child's fat }(\mathrm{g})\end{array}$ & 0.236 & 0.000 & $\begin{array}{l}\text { Mother's T2 \% energy from protein } \\
\text { Child's \% energy from fat }\end{array}$ & $0 \cdot 120$ & 0.008 & 0.087 & $-0.02,0 \cdot 19$ & 0.09 & $0 \cdot 161$ & $0.02,0.30$ & 0.02 & 0.052 & $-0.11,0.22$ & 0.54 \\
\hline $\begin{array}{l}\text { Mother's T1 fat }(\mathrm{g}) \\
\text { Mother's T2 fat }(\mathrm{g})\end{array}$ & $\begin{array}{l}0.085 \\
0.225\end{array}$ & $\begin{array}{l}0.05 \\
0.000\end{array}$ & $\begin{array}{l}\text { Mother's T1 \% energy from fat } \\
\text { Mother's T2 \% energy from fat }\end{array}$ & $\begin{array}{r}0.077 \\
-0.003\end{array}$ & $\begin{array}{l}0 \cdot 10 \\
0.96\end{array}$ & $\begin{array}{l}0.158 \\
0.011\end{array}$ & $\begin{array}{r}0.05,0.26 \\
-0.10,0.12\end{array}$ & $\begin{array}{l}0.004 \\
0.84\end{array}$ & $\begin{array}{l}0.051 \\
0.044\end{array}$ & $\begin{array}{l}-0 \cdot 10,0 \cdot 20 \\
-0 \cdot 12,0.21\end{array}$ & $\begin{array}{l}0.51 \\
0.60\end{array}$ & $\begin{array}{l}0.278 \\
0.001\end{array}$ & $\begin{array}{r}0.12,0.44 \\
-0.15,0.15\end{array}$ & $\begin{array}{l}0.001 \\
0.99\end{array}$ \\
\hline Child's carbohydrate (g) & & & Child's \% energy from carbohydrate & & & & & & & & & & & \\
\hline Mother's T1 carbohydrate (g) & 0.091 & 0.03 & Mother's T $1 \%$ energy from carbohydrate & 0.041 & 0.34 & 0.072 & $-0 \cdot 03,0 \cdot 17$ & 0.15 & 0.068 & $-0.07,0.21$ & $0 \cdot 29$ & 0.038 & $-0 \cdot 11,0 \cdot 19$ & $0 \cdot 61$ \\
\hline $\begin{array}{l}\text { Mother's T2 carbohydrate (g) } \\
\text { Child's fibre (q) }\end{array}$ & 0.250 & 0.000 & $\begin{array}{l}\text { Mother's T2 \% energy from carbohydrate } \\
\text { Child's fibre }(\mathrm{g} / 4184 \mathrm{~kJ})\end{array}$ & 0.047 & 0.27 & 0.060 & $-0 \cdot 04,0 \cdot 16$ & $0 \cdot 22$ & 0.073 & $-0 \cdot 06,0 \cdot 21$ & 0.34 & 0.078 & $-0.07,0.23$ & 0.30 \\
\hline Mother's T1 fibre (g) & 0.056 & 0.19 & Mother's T1 fibre $(\mathrm{g} / 4184 \mathrm{~kJ} \S)$ & 0.045 & 0.38 & 0.037 & $-0.09,0 \cdot 16$ & 0.56 & 0.089 & $-0.09,0.27$ & 0.33 & -0.03 & $-0 \cdot 23,0 \cdot 17$ & 0.77 \\
\hline Mother's T2 fibre (g) & 0.312 & 0.000 & Mother’s T2 fibre $(\mathrm{g} / 4184 \mathrm{~kJ})$ & 0.286 & 0.000 & 0.265 & $0.14,0.39$ & 0.000 & 0.247 & $0.04,0.46$ & 0.02 & $0 \cdot 227$ & $0.05,0.41$ & 0.01 \\
\hline
\end{tabular}

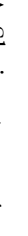


intake also demonstrated by the ALSPAC study ${ }^{(12)}$. Thus the present study is the second one to compare maternal prenatal-postnatal dietary intake influence on her young child's dietary intake. Our study has an added advantage of investigating this effect in children of pre-school age compared with ALSPAC study data on children of primary school age.

Our analysis provided a further addition to the previous literature by stratifying these prenatal-postnatal associations by children's breast-feeding status. The stratified analysis revealed that dietary intake associations for mother-child resemblances were generally stronger for breast-fed children. The exceptional association noted for maternal prenatal fat intake was observed only in nonbreast-fed children. Not breast-feeding and consuming fatty foods are both unhealthy behaviours and a possible explanation for the association may be that mothers practising unhealthy behaviours themselves go on to feed fatty foods to their children.

However, the ALSPAC investigators ${ }^{(12)}$ contended that the stronger maternal prenatal associations suggested maternal in utero programming of children's preferences. The finding that maternal prenatal fat-rich diet may program the offspring's preferences for fat intake has also been demonstrated in a number of animal studies ${ }^{(29-33)}$, which suggest that maternal prenatal intake of fatty palatable foods permanently alters offspring's in utero development and expression of central neural (reward related) and endogenous systems involved in regulation of preferences and intake of palatable (junk) foods ${ }^{(29-32)}$, even at the expense of protein- and fibre-rich foods ${ }^{(32)}$. The relevance of fat is attributed to a possible mechanistic explanation that its palatability is an important driving stimulus in dietary intake regulation ${ }^{(32)}$. Evidence suggests that infants' taste and preferences are formed with the earliest sensory perceptions from amniotic fluid (prenatal) or breast milk (postnatal) of the mother ${ }^{(34-36)}$. On the contrary, there is also evidence that formula feed flavours ${ }^{(37,38)}$ and post-weaning feeding practices influence children's conditioning of tastes ${ }^{(36,39)}$. Thus it may be difficult to disentangle these early-life effects from one another.

However, our analysis showed predominantly maternal postnatal associations for energy, energy-adjusted protein and fibre suggesting that mothers' influence through the shared food environment is still substantial.

The current study is the first three-generation family cohort analysis to demonstrate clear patterns of aggregation of dietary intake distinguishable along maternal and paternal lines. A key strength of the study was the inclusion of grandparents from both lineages, with maternal grandmothers' dietary information available at two time points. While numbers were modest, none the less the effects were consistently suggestive of a positive association in maternal grandmother-daughter dietary intake. Stafleu et al. ${ }^{(11)}$ had similarly shown a maternal-line association for maternal grandmothers' food, energy, fat and fatty acid intakes, although they did not have other grandparents' dietary data for comparisons. The observed association could be explained by a shared childhood environment where grandparents shape their children's (parents') dietary preferences, specifically with grandmothers imparting cookery skills to their daughters (mothers). However, this was unlikely to provide the full explanation considering that these grandparents and parents would usually live apart as adults. Moreover, our analyses did not demonstrate any association with paternal grandparents and also the homogeneity in intake among maternal grandmother-mother-child triads only improved with removal of maternal grandfathers from the maternal family line, suggesting again the maternal programming hypothesis of transmission. The maternal grandmother-mother-child relationship is unique in sharing an additional pathway of the womb in addition to other possible genetic and environmental pathways. Barker, the seminal author in this field, postulates that a 100-year period of nutritional flow from maternal grandmother and mother through the intra-uterine route may influence the health for life of an individual ${ }^{(40)}$. An explanation for the fetal origins hypothesis is that maternal provisioning is a conduit to transfer nutritional history of matrilineal ancestry to the fetus in order to align offspring to characteristics of the matrilineal line $e^{(41,42)}$.

Wang et $a l^{(1)}$ in their systematic review devised a sevencomponent score for judging methodological quality of the family resemblance studies (sample size of dyads, age range of children, method of dietary assessment, foods and nutrients analysed, types of parent-child pairs analysed, adjustment for confounders, and representativeness of sample). Based on these criteria, our study has a number of strengths.

It is a nationally representative cohort, whose sociodemographic profile has shown a match to Irish national survey data ${ }^{(43)}$. However, interpretation should be circumspect in that, as in most cohorts, there was a loss to follow-up over the period of 6 years, which may have introduced a degree of self-selection bias.

To our knowledge, our study is unique in having collected independent data in the same families for both prenatal and postnatal maternal dietary intake, and also data from fathers and all grandparent lines, probably unprecedented for paternal grandparents. It is also unique in collecting prenatal data for both parents at the same time point in early pregnancy.

Postnatal data were collected when the child was at a critical age, at school entry point. This allowed for a proper estimation of familial influence, before the children's diet would become influenced by the environment beyond the immediate family sphere. Although children may utilise institutional or non-institutional child-care services before regular school starts, adjustment for this variable in our study did not attenuate the observed pattern in mother-child associations. 
We employed a validated detailed FFQ which has been widely used internationally and which was specifically validated against a $7 \mathrm{~d}$ food diary in this cohort. Although maternal postnatal and other cohort members' dietary data were collected for their habitual diet for the preceding year, the maternal prenatal dietary data were collected for a relatively shorter duration of 3-4 months because it was intended to estimate her diet during pregnancy. It may be argued that this difference in reference period might have induced a bias, with maternal recall for her prenatal dietary data being relatively better. However, since maternal-paternal differences were not only seen with maternal prenatal but also with maternal postnatal and grandparental data, it is unlikely that this difference in recall period had any noteworthy impact. Furthermore, the maternal postnatal diet with a longer recall period actually showed stronger associations than the maternal prenatal diet.

Finally, our analyses were adjusted for a variety of potential confounders, including BMI and measures of social position.

The current study does have some acknowledged limitations. It is a relatively small cohort which may have implications for power considerations, but judging by sample sizes of most parent-child resemblance studies, our sample size was satisfactory. In fact if we applied the chosen criteria of Wang et al. ${ }^{(1)}$ for rating studies by sample size in their systematic review, our study qualifies for the highest score by this criterion.

Clearly only a third of fathers provided dietary data and not all grandparents participated. A comparison of nonresponders $v$. responders on sociodemographic profile showed that, as expected, responders had a relatively better social status; but all the same the anthropometric parameters of nutritional status were not different in both groups $^{(17)}$. Arguably this difference might have influenced the findings in that the most closely knit families participated. It is possible therefore that there is some systematic bias at play which could influence our outcome in producing stronger correlations for participating families, but this is unlikely to influence the differential patterns of associations observed in the matrilineal and patrilineal lines. Also, our findings with this prospective contemporary familial cohort are very consistent with findings from other published studies.

This cohort in a former analysis demonstrated a familial aggregation in BMI, with stronger effects of maternal-line influence ${ }^{(44)}$ and in the present analysis, even after controlling for familial BMI, we show a familial aggregation in dietary intake with similar patterns of stronger maternal-line influence. As the familial dietary associations are independent of BMI, the observed familial dietary aggregations are not attributable to familial resemblances in anthropometric measures ${ }^{(45)}$.

The Lifeways cohort has previously also shown a relationship between maternal diet during pregnancy and childhood asthma when the children averaged 3 years of age $^{(46)}$, so the cohort patterns of significant maternal gestational influence on outcomes of her child have been consistent over time.

The long-term significance for child health must be speculative. A systematic review and meta-analysis has shown that early-life shared environment does not necessarily translate into a significant contribution to childhood outcomes, such as obesity ${ }^{(47)}$. While in our analyses the correlations are consistent and statistically significant, they explain only a modest amount of the variance in the fully adjusted models. Children's development is influenced not just by maternal nutrition but also placental development and longer-term energy storage ${ }^{(40,48)}$. Davey Smith ${ }^{(49)}$ has cautioned that there are inherent methodological difficulties in distinguishing heritable, shared and non-shared environmental characteristics in family studies and noted especially that few studies track these familial associations into adulthood. None the less, if programming in early years is as critical as some authors suggest, then these early dietary patterns are important to document and good-quality mother and child health programmes that focus on child development beginning with the prenatal stage are warranted. Although still rare, some initiatives of such programmes are available (http://www.preparing forlife.ie/ $)^{(50)}$. Barker contends that the critical $1000 \mathrm{~d}$ period from pregnancy until the child is 2 years old is of profound importance, but also that grand-maternal influences are strongly influential ${ }^{(40,51-53)}$. In conclusion, our study provides empirical cross-generation evidence in human families that that is certainly the case in relation to nutrient intakes.

\section{Acknowledgements}

The Lifeways Cross-Generation Cohort Study was established as part of European Science Foundation-funded 'Social Variations in Health Expectancy in Europe' international research programme and its various sweeps have been funded by the Health Research Board of Ireland. The study is overseen by a scientific steering group whose members are (in alphabetical order): Professor Gerard Bury, Professor Leslie Daly, Professor Sean Daly, Dr Orla Doyle, Dr Una B. Fallon, Dr Frances B. Hannon, Dr Howard Johnson, Dr Lucy J. Jessop, Professor Cecily C. Kelleher, Professor B. Gerard Loftus, Professor John J. Morrison, Professor Andrew W. Murphy, Dr Celine Murrin, Dr Isabelle Niedhammer, Dr John O'Brien, Professor Helen Roche, Dr Aakash Shrivastava, Dr Mary Rose Sweeney, Professor Richard Tremblay and Dr Karien Viljoen. The authors declare that they have no conflict of interest in relation to the present paper. A.S. undertook all analyses reported in this paper and contributed to the interpretation of findings and paper drafting. C.M., M.R.S. and P.H. contributed to data collection at 5-year 
follow-up, interpretation of the current analysis and to providing critical revision of the paper. C.C.K. has been the principal investigator of all sweeps of the Lifeways cohort study since its establishment, oversaw the present analysis and contributed to the interpretation of findings and drafting of the paper. Each author has seen and approved the contents of the submitted manuscript. The authors greatly appreciate the participation of the Lifeways cohort families.

\section{References}

1. Wang Y, Beydoun MA, Li J et al. (2011) Do children and their parents eat a similar diet? Resemblance in child and parental dietary intake: systematic review and meta-analysis. J Epidemiol Community Health 65, 177-189.

2. Reed DR, Bachmanov AA, Beauchamp GK et al. (1997) Heritable variation in food preferences and their contribution to obesity. Behav Genet 27, 373-387.

3. Faith MS, Rha SS, Neale MC et al. (1999) Evidence for genetic influences on human energy intake: results from a twin study using measured observations. Behav Genet 29, 145-154.

4. de Castro JM (1993) Independence of genetic influences on body size, daily intake, and meal patterns of humans. Physiol Behav 54, 633-639.

5. Faith MS, Rhea SA, Corley RP et al. (2008) Genetic and shared environmental influences on children's 24-h food and beverage intake: sex differences at age 7 y. Am J Clin Nutr 87, 903-911.

6. Wardle J (1995) Parental influences on children's diets. Proc Nutr Soc 54, 747-758.

7. Savage JS, Fisher JO \& Birch LL (2007) Parental influence on eating behavior: conception to adolescence. J Law Med Ethics 35, 22-34.

8. Oliveria SA, Ellison RC, Moore LL et al. (1992) Parent-child relationships in nutrient intake: the Framingham Children's Study. Am J Clin Nutr 56, 593-598.

9. Fisher JO, Mitchell DC, Smiciklas-Wright $\mathrm{H}$ et al. (2002) Parental influences on young girls' fruit and vegetable, micronutrient, and fat intakes. J Am Diet Assoc 102, 58-64.

10. Lee Y \& Birch LL (2002) Diet quality, nutrient intake, weight status, and feeding environments of girls meeting or exceeding the American Academy of Pediatrics recommendations for total dietary fat. Minerva Pediatr 54, 179-186.

11. Stafleu A, Van Staveren WA, de Graaf C et al. (1994) Family resemblance in energy, fat, and cholesterol intake: a study among three generations of women. Prev Med $\mathbf{2 3}$ 474-480.

12. Brion MJ, Ness AR, Rogers I et al. (2010) Maternal macronutrient and energy intakes in pregnancy and offspring intake at $10 \mathrm{y}$ : exploring parental comparisons and prenatal effects. Am J Clin Nutr 91, 748-756.

13. O'Mahony D, Fallon UB, Hannon F et al. (2007) The Lifeways Cross-Generation Study: design, recruitment and data management considerations. Ir Med J 100, issue 8, suppl. 3-6.

14. National Nutrition Surveillance Centre (2003) Dietary Habits of the Irish Population: Results from SLÁN, Annual Report 2003. Dublin: National Nutritional Surveillance Centre, Department of Public Health Medicine and Epidemiology, University College Dublin and Health Promotion Unit, Department of Health and Children.

15. Harrington J (1997) Validation of a food frequency questionnaire as a tool for assessing nutrient intake. MA Thesis, National University of Ireland, Galway.
16. Gregory J, Collins D, Davies P et al. (1995) National Diet and Nutrition Survey: Children Aged 1.5-4.5 Years. vol. 1: Report of the Diet and Nutrition Survey. London: HMSO.

17. Murrin C (2011) Maternal factors during pregnancy contributing to early life risk of childhood obesity. PhD Thesis, University College Dublin.

18. Food Standards Agency (2002) McCance and Widdowson's The Composition of Foods, 6th summary edition. Cambridge: Royal Society of Chemistry.

19. Faith MS (2005) Development and modification of child food preferences and eating patterns: behavior genetics strategies. Int J Obes (Lond) 29, 549-556.

20. Willett WC, Howe GR \& Kushi LH (1997) Adjustment for total energy intake in epidemiologic studies. Am J Clin Nutr 65, 4 Suppl., 1220S-1228S.

21. Willett W \& Stampfer M (1998) Implications of total energy intake for epidemiologic analysis. In Nutritional Epidemiology, 2nd ed., pp. 273-301 [W Willett, editor]. Oxford: Oxford University Press.

22. Perusse L, Tremblay A, Leblanc C et al. (1988) Familial resemblance in energy intake: contribution of genetic and environmental factors. Am J Clin Nutr 47, 629-635.

23. Park HS, Yim KS \& Cho SI (2004) Gender differences in familial aggregation of obesity-related phenotypes and dietary intake patterns in Korean families. Ann Epidemiol 14, 486-491.

24. Borah-Giddens JF \& Falciglia GA (1993) A meta-analysis of the relationship in food preferences between parents and children. J Nutr Educ 25, 102-107.

25. Patterson TL, Rupp JW, Sallis JF et al. (1988) Aggregation of dietary calories, fats, and sodium in Mexican-American and Anglo families. Am J Prev Med 4, 75-82.

26. Beydoun MA \& Wang Y (2009) Parent-child dietary intake resemblance in the United States: evidence from a large representative survey. Soc Sci Med 68, 2137-2144.

27. Davey Smith G (2008) Assessing intrauterine influences on offspring health outcomes: can epidemiological studies yield robust findings? Basic Clin Pharmacol Toxicol 102, 245-256.

28. Davey Smith G, Leary S, Ness A et al. (2009) Challenges and novel approaches in the epidemiological study of early life influences on later disease. Adv Exp Med Biol 646, $1-14$

29. Vucetic Z, Kimmel J, Totoki K et al. (2010) Maternal high-fat diet alters methylation and gene expression of dopamine and opioid-related genes. Endocrinology 151, 4756-4764.

30. Chang G-Q, Gaysinskaya V, Karatayev O et al. (2008) Maternal high-fat diet and fetal programming: increased proliferation of hypothalamic peptide-producing neurons that increase risk for overeating and obesity. J Neurosci $\mathbf{2 8}$, 12107-12119.

31. Ong ZY \& Muhlhausler BS (2011) Maternal 'junk-food' feeding of rat dams alters food choices and development of the mesolimbic reward pathway in the offspring. FASEB J 25, 2167-2179.

32. Bayol SA, Farrington SJ \& Stickland NC (2007) A maternal 'junk food' diet in pregnancy and lactation promotes an exacerbated taste for 'junk food' and a greater propensity for obesity in rat offspring. Br J Nutr 98, 843-851.

33. Levin BE (2008) Epigenetic influences on food intake and physical activity level: review of animal studies. Obesity (Silver Spring) 16, Suppl. 3, S51-S54.

34. Mennella JA, Jagnow CP \& Beauchamp GK (2001) Prenatal and postnatal flavor learning by human infants. Pediatrics 107, E88.

35. Schaal B, Marlier L \& Soussignan R (2000) Human foetuses learn odours from their pregnant mother's diet. Chem Senses 25, 729-737.

36. Forestell CA \& Mennella JA (2007) Early determinants of fruit and vegetable acceptance. Pediatrics 120, 1247-1254. 
37. Mennella JA \& Beauchamp GK (2002) Flavor experiences during formula feeding are related to preferences during childhood. Early Hum Dev 68, 71-82.

38. Mennella JA, Kennedy JM \& Beauchamp GK (2006) Vegetable acceptance by infants: effects of formula flavors. Early Hum Dev 82, 463-468.

39. Harris G (2008) Development of taste and food preferences in children. Curr Opin Clin Nutr Metab Care 11, 315-319.

40. Barker DJP (2012) Sir Richard Doll Lecture. Developmental origins of chronic disease. Public Health 126, 185-189.

41. Kuzawa CW (2005) Fetal origins of developmental plasticity: are fetal cues reliable predictors of future nutritional environments? Am J Hum Biol 17, 5-21.

42. Kuzawa CW (2007) Developmental origins of life history: growth, productivity, and reproduction. Am J Hum Biol 19, 654-661.

43. Niedhammer I, O'Mahony D, Daly S et al. (2009) Occupational predictors of pregnancy outcomes in Irish working women in the Lifeways cohort. BJOG 116, 943-952.

44. Murrin CM, Kelly GE, Tremblay RE et al. (2012) Body mass index and height over three generations: evidence from the Lifeways cross-generational cohort study. BMC Public Health 12, 81.

45. Faith MS, Keller KL, Johnson SL et al. (2004) Familial aggregation of energy intake in children. Am J Clin Nutr 79, 844-850.
46. Fitzsimon N, Fallon U, O'Mahony D et al. (2007) Mothers' dietary patterns during pregnancy and risk of asthma symptoms in children at 3 years. Ir Med J 100, issue 8, suppl. 27-32.

47. Silventoinen K, Rokholm B, Kaprio J et al. (2010) The genetic and environmental influences on childhood obesity: a systematic review of twin and adoption studies. Int J Obes (Lond) 34, 29-40.

48. Eriksson JG, Kajantie E, Thornburg KL et al. (2011) Mother's body size and placental size predict coronary heart disease in men. Eur Heart J 32, 2297-2303.

49. Davey Smith G (2011) Epidemiology, epigenetics and the 'Gloomy Prospect': embracing randomness in population health research and practice. Int J Epidemiol 40, 537-562.

50. Doyle O, McNamara KA, Cheevers C et al. (2010) Preparing for Life Early Childhood Intervention. Impact Evaluation Report 1: Recruitment and Baseline Characteristics. UCD Geary Institute Working Paper Series no. WP2010/50. Dublin: Geary Institute, University College Dublin; available at http://www.ucd.ie/geary/static/publications/workingpapers/ gearywp201050.pdf

51. Barker DJP (2004) The developmental origins of adult disease. J Am Coll Nutr 23, 6 Suppl., 588S-595S.

52. Bateson P, Barker D, Clutton-Brock $\mathrm{T}$ et al. (2004) Developmental plasticity and human health. Nature $\mathbf{4 3 0}$, 419-421.

53. Barker DJP (2007) Obesity and early life. Obes Rev 8, 45-49. 